\title{
EXPERIÊNCIAS DE ENSINO E APRENDIZADO DE LÍNGUA INGLESA NO ENSINO SUPERIOR DENTRO DE UMA PROPOSTA DE MULTIMODALIDADE E LETRAMENTO CRÍTICO
}

\author{
Learning and teaching English experiences in higher education within a multimodality and \\ critical literacy approach
}

William Mineo TAGATA - UFU (Universidade Federal de Uberlândia)

RESUMO: O objetivo deste artigo é discutir questões de letramento crítico e de multiletramentos a partir de minha experiência como professor de língua inglesa em uma universidade brasileira. Essa experiência levou a uma reflexão sobre a importância da linguagem visual e sua relação com a linguagem verbal, tanto no contexto da cultura ocidental em que estou situado, quanto em uma cultura indígena brasileira. No fim, defendo a importância do letramento crítico para o ensino de línguas, de modo a conscientizar o aluno do caráter multimodal e híbrido da linguagem, e de suas implicações éticas.

PALAVRAS-CHAVE: ensino de línguas; multimodalidade; letramento crítico; visualidade; hibridismo; reflexividade.

ABSTRACT: This paper aims to discuss questions of critical literacy and multiliteracies based on my experience as an English teacher in a Brazilian university. This experience has led to a reflection about the importance of visuality and its relation to verbal language, not only in the context of the Western culture in which I am embedded, but also in the context of a Brazilian indigenous culture. In the end, I advocate the importance of critical literacy for language education, in order to make students aware of the hybrid and multimodal character of language, as well as its ethical implications.

KEYWORDS: multimodality; critical literacy; visuality; hybridity; reflexivity.

Through others I am somebody. (provérbio africano)

J'allais chercher des images: voilà tout. (François-René Chateaubriand)

Este artigo nasceu como um conjunto de notas sobre minhas experiências como professor de língua inglesa em um curso de graduação de Letras. Também é fruto de algumas reflexões sobre as leituras que realizei por minha participação em um projeto de âmbito nacional envolvendo outros 
professores de universidades públicas brasileiras ${ }^{1}$. Tal projeto constitui um espaço de discussões sobre o ensino de línguas a partir de uma proposta de letramento crítico e de novos letramentos proposta que, a meu ver, pode se coadunar com os objetivos e conteúdos trabalhados nas duas disciplinas que ministro atualmente em uma universidade pública brasileira.

O Projeto Político Pedagógico atualmente em voga no curso de Letras em que leciono parece refletir boa parte das preocupações norteadoras dos estudos de novos letramentos, como atesta o seguinte excerto do Projeto (2007, s/n):

O Curso de Letras da UFU buscará preparar o futuro profissional não só para enfrentar um contexto sóciohistóricoeconômico e cultural dinâmico e competitivo, mas, sobretudo, para atuar como leitor crítico - no sentido amplo do termo - e como agente eficaz na construção da cidadania e, portanto, capaz de fazer uso da linguagem, notadamente a verbal, nas suas diferentes manifestações [...] A descrição e a explicação do funcionamento geral da língua deve levar em conta as suas condições de produção, ou seja, a atividade de produtores/receptores de texto situados em contextos reais e submetidos a decisões que seguem estratégias nem sempre dependentes apenas do que se convencionou chamar de sistema linguístico.

O leitor crítico idealizado pelo Projeto Pedagógico do curso se constitui como cidadão letrado, ou seja, possui e utiliza um conhecimento dos usos sociais e culturais da linguagem, sendo capaz de relacionar diferentes instanciações de uso da linguagem a seus contextos específicos de produção e de recepção, e de determinar os fatores contextuais que influenciam as escolhas linguísticas. Embora o Projeto do curso de Letras destaque a centralidade da linguagem "notadamente" verbal, parece-me importante ampliar o escopo de abrangência dos estudos da linguagem realizados no curso de Letras, de modo que se possa levar em conta o caráter multimodal da comunicação humana. Dessa forma, será possível abrir espaço para o estudo de diferentes manifestações da linguagem, como a visual, a gestual, a eletrônica, etc.

$\mathrm{O}$ conceito de multimodalidade se baseia na ideia de modo enquanto um "meio semioticamente articulado de representação e de comunicação" (KRESS, 2000, p.185). Nessa concepção, a escrita, a imagem, e o gestual, entre outros, seriam modos semióticos distintos, mas usados simultaneamente, quer na escrita ou na oralidade. O autor (2000) sugere que tanto a linguagem escrita quanto a oral são multimodais: a primeira compreende modos semióticos tão distintos quanto a grafologia, a paginação, e o uso de cores, enquanto a segunda utiliza recursos como ritmo, entonação, volume, entre outros. Para o autor, portanto, todo e qualquer texto, assim

\footnotetext{
${ }^{1} \mathrm{O}$ projeto "Formação de professores nas teorias nos novos letramentos e multiletramentos: o ensino crítico de línguas estrangeiras na escola”, coordenado pelos professores Walkyria Monte Mor e Lynn Mário Trindade Menezes de Souza (FFLCH/USP), teve início no segundo semestre de 2009, em um encontro com professores de universidades estaduais e federais brasileiras, convidados pelos coordenadores a participarem do projeto através de ações locais em programas de educação continuada com professores de escolas públicas. O projeto prevê o planejamento e a implementação de ações pedagógicas no ensino de línguas, tendo em vista as necessidades locais avaliadas, e baseando-se nos estudos sobre letramento crítico e multiletramentos.
} 
como todo e qualquer sistema de comunicação, é necessariamente multimodal, embora em um determinado texto possa predominar um modo semiótico específico. Um dos modos que mais interessam a esse autor em particular é o da visualidade, sobre a qual realizou vários estudos (KRESS \& van LEEUWEN, 1998; KRESS, 2000; KRESS, 2009).

A importância da imagem levou Kress a sugerir a inclusão do tema em programas de educação formal. Segundo o autor (2009), há vários motivos pelos quais o estudo da imagem é fundamental na formação de cidadãos preparados para encarar os desafios da comunicação multimodal em tempos atuais. Primeiro, porque a linguagem visual constitui um meio cada vez mais importante de codificação de nossas experiências e interações sociais; segundo, porque a comunicação visual tem seus próprios meios de expressão semiótica, diferentes do verbal. Para Kress \& van Leeuwen (1998), por exemplo, usamos esses dois sistemas semióticos para codificar nossas experiências de mundo, sendo que cada um dos sistemas tem suas próprias maneiras de fazê-lo. Às vezes, uma ideia pode ser expressa em palavras e imagens; outras, é mais facilmente expressa de uma forma que de outra, e ainda há casos em que não consegue se expressar através de um ou de outro. Kress \& van Leeuwen ainda mencionam um terceiro motivo pelo qual a comunicação visual deveria fazer parte de nossa formação acadêmica: "os meios de comunicação visual são expressões racionais de significados culturais, passíveis de explicações racionais e análises constitutivas" (KRESS \& van LEEUWEN, 1998, p.20).

Essas análises constitutivas, segundo os autores, podem se ocupar das diversas formas de imbricação entre imagem, texto escrito e outros elementos gráficos que caracterizam a mídia impressa atualmente, assim como as mudanças que se operam sobre nossas subjetividades; afinal, "o mundo representado visualmente pela mídia de massa é um mundo diferente - e produz diferentes sujeitos/cidadãos - do mundo representado pela língua” (KRESS \& van LEEUWEN, 1998, p.31). Os autores chegam a essa conclusão após uma análise de livros didáticos de ciências para crianças inglesas, em que a presença maciça de imagens leva os autores à hipótese de que essas crianças desenvolvem uma noção diferente do que seja a ciência, seu status como disciplina, o papel do cientista, entre outras questões epistemológicas.

As diversas formas de imbricação entre as linguagens verbal e visual características no atual cenário semiótico pedem uma redefinição das fronteiras entre palavra e imagem. No campo da semiótica social, por exemplo, um estudo sobre a tipografia realizado por van Leeuwen (2005) revela que, em tempos de comunicação mediada por computadores, "a escrita se torna mais visual e a imagem mais parecida com a escrita" (2005, p.43), confundindo as fronteiras entre as linguagens, e colocando em xeque a separação entre o pesquisador acadêmico e o artista. Essas mudanças acabam 
alterando as relações de poder entre os diferentes meios semióticos: a presença ubíqua da linguagem visual em jornais, revistas, livros, anúncios publicitários, etc., de acordo com van Leeuwen (2005), pode ser vista como uma ameaça por uma elite acostumada à hegemonia da palavra. À medida que a presença e o prestígio da imagem na mídia impressa aumentam, conforme sugere o autor, surgem iniciativas para regular, controlar ou prescrever seus significados, através da publicação de manuais dedicados à análise de imagens ou da criação de cursos especializados no assunto, por exemplo. Em contrapartida, a linguagem verbal perdeu parte do prestígio de que gozava, levando a uma relativa desvalorização do domínio de regras gramaticais e ortográficas; o autor exemplifica sua afirmação citando o uso de formas gramaticais tidas como desviantes da norma padrão em textos publicitários. Essas mudanças, como o autor (2005) faz questão de frisar, sempre têm um componente ideológico: tanto imagens quanto palavras nunca apenas representam ou reproduzem a realidade social em que estão inseridas, mas elas produzem versões da realidade sempre comprometidas com determinados interesses de indivíduos ou instituições sociais. Além disso, posto que esses indivíduos ou grupos possuem interesses diferentes e até conflitantes, os textos - verbais ou imagéticos - por eles produzidos vão refletir as diferenças e conflitos característicos do meio social híbrido de que fazem parte. O mesmo acontece com a questão da recepção ou interpretação desses textos, aos quais muitas vezes atribuímos significados conflitantes.

Ao destacar a importância dos contextos de produção e de recepção de textos em seu estudo, o Projeto Político Pedagógico do curso de Letras em que leciono pode não só ajudar o aluno a compreender - sem a promessa de resolver ou acomodar - esses conflitos de interpretação inerentes ao processo de comunicação multimodal, mas também a se posicionar criticamente em relação ao componente ideológico de quaisquer textos, e aos interesses que guiam sua elaboração, circulação e recepção. Nas duas disciplinas de graduação do curso de Letras que tive a oportunidade de ministrar até agora, essas questões vêm orientando o planejamento e a execução de algumas ações pedagógicas.

Uma das disciplinas que lecionei foi "Língua Inglesa: Fundamentos Linguísticos", no segundo semestre de 2009, pela primeira vez, e agora, pela terceira vez, no segundo semestre de 2011. A ementa da disciplina a descreve como "um estudo dos mecanismos de funcionamento da língua inglesa, dentro de uma concepção de língua como instrumento de comunicação e como uma prática social, constituída também por uma dimensão ético-política” (BRASIL, 2007, s/n). Portanto, ao final do curso, espera-se que o aluno tenha uma boa noção das formas de organização da língua inglesa em diferentes níveis - morfológico, sintático, textual e discursivo - e suas funções em contextos comunicativos diferentes, além de permitir uma reflexão sobre as implicações de cunho 
ético, político e ideológico das escolhas linguísticas. Desde o início, minha seleção de materiais e atividades pedagógicas e sua forma de utilização em aula, foram pautadas pela preocupação em desfazer o mito da neutralidade da linguagem, em quaisquer de suas modalidades, até mesmo na linguagem visual ${ }^{2}$, e pela necessidade de refletir sobre suas condições locais, parciais e específicas de produção e recepção. Para tanto, propus o estudo de uma série de textos em língua inglesa, característicos dos gêneros textuais (SWALES, 1999) que havia selecionado para a disciplina.

O uso de gêneros em contexto educacional é justificado por vários autores engajados com estudos sobre novos letramentos, como Street (2005). Para o autor, um estudo sobre os usos e significados sociais de letramentos deve analisar "os gêneros, estilos e discursos associados com os letramentos mobilizados para propósitos educacionais e as relações subjacentes de poder institucional em que essas práticas de letramento se baseiam" (STREET, 2005, p.5). Tal análise pode, assim, ajudar a formar o leitor crítico idealizado pelo Projeto Pedagógico do curso de Letras a que nos referimos acima, justificando, portanto, o trabalho com gêneros realizado na disciplina de língua inglesa em questão. Nessa disciplina, cada texto lido em aula deveria levar ao estudo de determinados aspectos linguisticos. Assim, por exemplo, no estudo do gênero acadêmico "abstract", pareceu-me oportuno propor um estudo da voz passiva em inglês, visto sua grande ocorrência em textos desse gênero.

Durante e após a análise, teóricos como Kress (2000, 2009), Gee (2004) e Cope \& Kalantzis (2000) foram frequente e extensamente mencionados. Como dissemos antes, era importante questionar a neutralidade da linguagem, e desencadear uma reflexão sobre as condições ou contextos de produção e interpretação dos textos. Um dos slides preparados para apresentação em aula, sobre a impossível neutralidade da linguagem, apresentava essa questão da seguinte forma:

In the end, the point is that no wording is ever neutral or just "the facts". All wordings - given the very nature of language - are perspectives on experience that exist alongside of competing perspectives in the grammar of the language and in actual social interactions (GEE, 2004, p.54).

Segundo Gee, a linguagem coloca à disposição dos usuários uma série de recursos gramaticais cuja seleção e utilização revela uma determinada perspectiva ou ponto de vista dos usuários diante da realidade dos "fatos", nunca objetivos ou neutros. Uma das aulas em que a tese de Gee foi amplamente corroborada teve como tema o gênero notícia de jornal. No começo da aula,

\footnotetext{
${ }^{2}$ Uma das autoras que questionam a aparente neutralidade da linguagem fotográfica é Rose (2007). Através da análise de uma fotografia tirada pelo fotógrafo francês Doisneau, a autora demonstra como, longe de constituir uma representação inocente, objetiva ou puramente documental da realidade, a fotografia, assim como outras formas de linguagem visual, pressupõe ou é sempre construída através de várias tecnologias, conhecimentos e práticas sociais e culturais específicas.
} 
apresentei três manchetes de artigos de jornais ingleses publicados na Internet no mesmo dia, noticiando o mesmo "fato". Elas diziam respeito a um incidente diplomático entre Brasil e Inglaterra, por ocasião do envio de lixo tóxico hospitalar oriundo da Inglaterra para o porto de Santos: “Britain's dirty little secret as a dumper of toxic waste" (texto A); "Gangs making millions by illegally dumping toxic waste" (texto B); "Waste companies face inquiry as British rubbish is returned from Brazil” (texto C). A análise das manchetes - seguida pela análise dos respectivos artigos - procurou apontar como os textos A e B ganhavam contornos sensacionalistas através de vocabulário relacionado a crime ou ilegalidade, como "dirty secret", "gangs", "illegally", enquanto o texto C adotava um tom aparentemente mais imparcial, falando em "waste companies" - portanto, deixando de atribuir a responsabilidade do erro ao país, como no caso da primeira manchete -, e utilizando a voz passiva para ocultar o agente da ação. Além disso, a escolha do substantivo (“dumper”) para se referir ao país no texto A confere um tom de acusação mais grave do que no texto B, cuja manchete optava pelo uso do verbo ("dumping"), sugerindo um tom mais circunstancial e menos taxativo do que a primeira manchete. Pudemos observar também como o uso do verbo implicava uma dinamicidade processual, ao passo que o substantivo tendia à essencialização ou à atribuição permanente de certas características a seu possuidor. Por fim, enquanto as manchetes A e B destacam a toxicidade do lixo, a manchete C se limita a informar sua origem ("British rubbish").

Para o prosseguimento da análise, baseada nos textos que acompanhavam as três manchetes, a classe foi dividida em três grupos, sendo cada grupo responsável por cada um dos artigos. O objetivo era responder algumas questões de compreensão geral e específica do texto, além de questões sobre aspectos gramaticais específicos. Porém, de modo geral os alunos tiveram bastante dificuldade em realizar a atividade proposta, alegando falta de conhecimento de vocabulário da língua inglesa. A situação se repetiu em outras aulas centradas na leitura e análise de textos em inglês, gerando frustração para os alunos e para o professor. O pouco conhecimento de língua inglesa por parte da turma poderia comprometer o tipo de análise que havia sido planejado, de modo a desenvolver a consciência crítica dos alunos em relação à linguagem, conforme previsto no Projeto Pedagógico? Como lidar com os diferentes níveis de conhecimento linguístico dos alunos, além de níveis de motivação diferentes?

Pareceu-me uma boa saída trazer para a aula e explorar textos ricamente ilustrados, com muita informação visual que pudesse facilitar a compreensão do verbal. Um dos três artigos de jornal da internet utilizados na aula descrita, por exemplo, trazia a foto de um dos contêineres vindos da Inglaterra aberto, sendo possível ver parte do lixo hospitalar em seu interior. Ainda durante o trabalho com o gênero notícia de jornal, passamos algum tempo analisando as fotos que 
acompanhavam os textos escritos, e as relações entre imagem e texto. Que tipo de comentários as imagens representavam em relação ao texto verbal? A relação era de complementaridade? Contraste? Haveria aspectos da imagem não-ditos no texto, ou vice versa? De que formas a imagem destacava ou enfatizava certos aspectos da notícia? Para mim, a ideia de impossível neutralidade ou objetividade da linguagem, comentada por Gee (2004) e apresentada em aula no slide mencionado anteriormente, também se aplicava à imagem, como cheguei a mencionar em aula. $\mathrm{O}$ interesse de Gee, no entanto, se restringe à palavra, como o próprio autor sugeriu na citação anterior:

In the end, the point is that no wording is ever neutral or just "the facts". All wordings - given the very nature of language - are perspectives on experience that exist alongside of competing perspectives in the grammar of the language and in actual social interactions (GEE, 2004, p.54).

Em outro momento do mesmo estudo, Gee (2004) reafirma seu interesse pela linguagem verbal, e a centralidade desta nas pesquisas sobre novos letramentos e multiletramentos. Para o autor, na perspectiva dos estudos de novos letramentos, dificilmente pode-se falar em letramento como algo único, pois parece haver tantos letramentos quanto práticas socioculturais distintas em que a linguagem escrita se insere; por exemplo, as mensagens postadas pelos fãs em um site dedicado a um mangá japonês (GEE, 2004, p.91) - de novo, a ênfase na linguagem escrita. A modalidade escrita que mais interessa ao autor é o que ele chama de linguagem acadêmica, presente em ambientes educacionais e em outras instituições burocrático-administrativas, disciplinares e profissionais. Segundo o autor (2004), se essa modalidade de letramento já chegou um dia a ser considerada um componente central do currículo de programas educacionais bem sucedidos, hoje em dia sabe-se que seu conhecimento é uma condição necessária, porém insuficiente, para uma boa formação educacional, sintonizada com as demandas do mercado de trabalho criadas pelo que o autor chama de "novo capitalismo" (2004). Para atender a essas demandas, de acordo com Gee, é preciso que a escola trabalhe com novas concepções de linguagem, cultura e conhecimento, aliando o estudo da linguagem acadêmica ao desenvolvimento de outras formas de letramento, como o digital e o visual, entre outros. Desse modo, será possível promover uma consciência crítica dos usos sociais e culturais da linguagem, e das implicações desses usos para a formação de identidades em diferentes contextos; em outras palavras, uma consciência de que as pessoas usam diferentes variedades de linguagem para fins e em contextos específicos, "ao mesmo tempo em que atuam como determinados tipos de pessoas com pontos de vista, valores e maneiras de agir, falar e pensar característicos" (GEE, 2004, p.93). A julgar pela ênfase do autor anteriormente dada à palavra, no momento em que o autor defende a importância do desenvolvimento de novas concepções de linguagem, cultura e 
conhecimento em ambiente educacional, devemos supor que essa "linguagem", para Gee, é eminentemente verbal, ou também pressupõe a imagem?

A centralidade da palavra para os estudos de novos letramentos também aparece implicitamente em outros estudos sobre novos letramentos, como o de Cope e Kalantzis (2000), para quem letramentos constituem "socially recognised ways of generating, communicating and negotiating meaningful content through the medium of encoded texts" (2000, p.15). Novamente, é visível o interesse maior dos pesquisadores pela linguagem verbal, como no caso de Gee. Esse interesse não chega a surpreender, considerando nossa participação em uma sociedade ainda caracterizada pela primazia da palavra em relação a outros modos semióticos. No caso das experiências de letramento crítico aqui descritas, também não é diferente. Hoje, ao refletir sobre essas experiências, percebo que minha opção por trabalhar com imagens nas aulas acima referidas se deu não apenas por minha crença na importância do estudo da multimodalidade, mas também pela expectativa de que a linguagem visual poderia auxiliar os alunos menos proficientes em inglês a compreender o texto verbal - ou seja, o visual como complemento do verbal. Mas o que aconteceria em uma sociedade ágrafa, ou em outras sociedades em que a palavra não tenha um papel preponderante? Que tipos de letramento seria possível encontrar nessas sociedades, e que formas de conhecimento estariam associadas a esses letramentos? Como se caracterizariam os processos de construção e negociação de sentido em um mundo sem escrita? Haveria conflitos de interpretação semelhantes àqueles com os quais nos deparamos?

Interessado na questão do letramento indígena numa comunidade de índios kashinawás no Brasil, Menezes de Souza (2002) faz uma reflexão instigante sobre o impacto da introdução da escrita alfabética numa cultura ágrafa como a dos kashinawás. O traço característico mais saliente dessa cultura é o que o autor chama de performatividade, que consiste no poder das narrativas orais, entre outras práticas culturais, enquanto performance, ou seja, como um ato social e dinâmico onde o conhecimento da comunidade é construído e reconstruído, e seus valores e crenças transmitidos. Trata-se, portanto, de um ponto de vista radicalmente diferente da idéia essencialista de cultura vigente na cosmologia ocidental, onde o conhecimento é definitivamente sacralizado através da escrita - amiúde tida como uma versão melhorada, mais confiável e definitiva do que a oralidade, vista com desconfiança por gozar de menos prestígio social do que a escrita - e transmitida de uma geração a outra ao longo da linearidade inexorável do tempo histórico, por meio da imortalidade dos livros. Por outro lado, a performatividade dos kashinawás faz com que os significados de sua cultura estejam permanentemente abertos à renovação e ao devir, pois na interação com sua platéia o narrador os invoca e modifica conforme seu ponto de vista e o contexto imediato em que se 
desenrola a interação. Com isso, o momento da performance - que é também o momento em que os valores e os conhecimentos da comunidade vão sendo construídos e reconstruídos - será único e não repetível.

O que acontece então quando uma comunidade ágrafa como a dos kashinawás entra em contato com a cultura escrita ocidental? A introdução da escrita alfabética nessa comunidade, de acordo com Menezes de Souza, deu início a um processo de tradução cultural, visível na maneira como essa escrita foi apropriada pelos kashinawás ao realizarem a transposição de suas narrativas orais para a escrita, gerando uma forma de escrita híbrida e multimodal. O status de multimodal dado pelo autor às narrativas produzidas por membros dessa comunidade se justifica por seu uso simultâneo de linguagens verbais e não-verbais na mesma narrativa. Há duas instâncias de linguagem não-verbal presentes na narrativa escrita kashinawá, ou dois tipos de desenho: o dami, que consiste de desenhos figurativos representando homens, animais, plantas e outros elementos da natureza; e o kenê, que se trata de um conjunto de traços geométricos abstratos, inspirados na pele da cobra jibóia ou anaconda (a qual muda constantemente de pele para poder sobreviver, e que para os kashinawás está relacionada com o mito da chegada do conhecimento e da cultura), e passíveis de serem usados juntamente com os desenhos dami e com textos verbais de escrita alfabética. Através de entrevistas com membros da comunidade kashinawá, Menezes de Souza (2002) descobriu que na narrativa multimodal kashinawá a linguagem visual é mais importante do que a escrita alfabética, resultado do contato com o homem branco. Para os kashinawás, a escrita do homem branco possui um valor enquanto proposição, precisando ser complementado pelo potencial performático do kenê. O uso de desenhos kenê confere legitimidade ao que está sendo narrado, sinalizando "a presença nesse texto de algo semelhante a um processo, uma transformação valorizada e indicam, portanto, que tal texto possui um alto grau de legitimação e veracidade". Por outro lado, a ausência completa de desenhos kenê ou dami numa narrativa a destitui do potencial de transmitir uma mensagem para a comunidade, ou seja, a presença da escrita alfabética por si só não constitui um texto para os kashinawás.

Ao absorver e transformar a escrita alfabética do homem branco, os kashinawás fazem uma tradução cultural da escrita grafocêntrica que, de acordo com Menezes de Souza (2001), nos convida a refletir sobre "as complexidades dos processos heterogêneos da escrita e a sua imbricação em práticas socioculturais e ideológicas”. Uma dessas reflexões sobre diferentes instâncias de letramento como as dos kashinawás diz respeito à insuficiência ou às limitações de nossa visão de mundo e do aparato teórico e conceitual que utilizamos para compreendermos o mundo, o lugar que ocupamos nele e nossa relação com os outros. Quando nos damos conta da parcialidade de nossos valores culturais, percebemos a arrogância equivocada daqueles que atribuem a uma cultura ágrafa como a 
dos kashinawás o status de inferior, sendo incapazes de apreciar o valor dessas culturas "orais" epíteto, diga-se de passagem, somente utilizável por uma cultura "não-oral” -, cujas manifestações artísticas e processos de construção de conhecimento envolvem o uso de gestos, ritos e os sentidos do tato, do olfato e do paladar. É a essa arrogância que a antropóloga Manuela Carneiro da Cunha (2009) parece estar se referindo ao lembrar que existem muito mais regimes de verdade e de conhecimento do que nossa vã filosofia ocidental pode imaginar.

O reconhecimento de que nossa percepção do mundo está firmemente ancorada na escrita pode nos ajudar a perceber que outras formas de conhecimento são possibilitadas por uma relação mais sinestésica com o mundo, que não dependem tanto ou tão-somente da escrita. A ideia de sinestesia é colocada da seguinte forma por Kress (apud MENEZES DE SOUZA, 2001, s/n):

\footnotetext{
Maneiras diferentes de construir o significado envolvem formas diferentes de engajamento corporal com o mundo - isto é, não apenas através da visão, como ocorre com a escrita, ou através da audição, como ocorre com a fala, mas também através do tato, do olfato, do gosto, da sensação. Se concordamos que a fala e a escrita levam a formas específicas de escrita, então devemos pelo menos perguntar se o tato, o gosto, o olfato, a sensação também levam a formas específicas de pensar. Em nosso pensamento, inconsciente ou conscientemente, nós traduzimos constantemente de um meio para outro. Essa habilidade e esse fato da sinestesia é essencial para que os seres humanos compreendam o mundo $(2001, \mathrm{~s} / \mathrm{n})$.
}

Se um maior "engajamento corporal" com o mundo leva a maneiras diferentes de construir o significado, poderíamos refletir sobre as limitações advindas de uma forma de apreender o mundo e de construir significados calcada apenas na leitura e na escrita. Que tipo de conhecimento, por exemplo, nos é inacessível por causa das deficiências causadas por nossa dependência em relação à leitura e à escrita? O que a cosmologia indígena pode nos ensinar a respeito do modo como interagimos com o mundo, os letramentos que utilizamos, e os conhecimentos que construímos nessa interação? O que sabem os kashinawás que nós não sabemos, por causa de seu excedente de visão em relação a nós? Nunca é demais lembrar a especificidade de nossos pontos de vista, segundo a qual os sentidos que atribuímos às coisas são determinados pela posição ideológica que ocupamos no mundo, sendo-nos vedado o acesso à totalidade ou o conhecimento de uma verdade absoluta. Essa consciência da parcialidade ou especificidade da perspectiva do pesquisador é o que muitos teóricos chamam de reflexividade. Para Rose (2007), a reflexividade pode ajudar a conter os impulsos de totalização ou universalização do conhecimento acadêmico, e lembrar o pesquisador de que o letramento e o conhecimento acadêmicos, assim como todas as outras formas de letramento e de conhecimento, são necessariamente situados e específicos, aplicáveis a um contexto social determinado. Segundo a autora (2007, p.136), 
Reflexivity is thus about the position of the critic, about the effects that position has on the knowledge that the critic produces, about the relation between the critic and the people or materials they deal with, and about the social effects of the critic's work.

Nesse sentido, a postura de qualquer pesquisador engajado com o estudo de novos letramentos, letramento crítico ou multiletramentos deveria ser, necessariamente, reflexiva. Entendo letramento crítico à maneira de Menezes de Souza (2011), para quem o leitor crítico lê se lendo, ou seja, tem consciência de como constrói o significado: por que entendi assim? Por que acho isso? De onde vieram as minhas ideias, as minhas interpretações? Assim, uma pesquisa em letramento critico ou novos letramentos deve partir da premissa de que as formas de letramento ou de produção de sentidos que fundamentam a investigação são apenas uma entre tantas outras formas de letramento, e estão circunscritas a um contexto social, cultural e político específico. Dessa forma, poderemos manter nossa imaginação aberta a outros letramentos, como os dos índios kashinawás, por exemplo, ou aqueles caracterizados por uma relação mais sinestésica com o mundo, e assim lançar um olhar crítico sobre nossos letramentos. Em tempos de comunicação mediada por computadores, a centralidade da escrita no letramento acadêmico já começa a ser desafiada, conforme revela o estudo sobre tipografia realizado por van Leeuwen (2005) ao qual já aludimos antes, que sugere uma reconfiguração atual das fronteiras entre as linguagens verbal e visual, por um lado, e entre o pesquisador acadêmico e o artista, por outro lado, com profundas consequências epistemológicas. Diante desse cenário multimodal, só nos resta reconhecer as limitações e especificidades de um letramento fortemente ancorado na escrita, de modo que possamos atribuir à imagem sua devida importância enquanto forma de letramento, não necessariamente subserviente em relação à escrita, e merecedora de seus próprios modelos de análise ou interpretação.

Felizmente, vários estudos têm sido dedicados ao tema. Street (2005) defende a necessidade de aproximar o conceito de letramento acadêmico a outras práticas comunicativas, como a visualidade, de forma a superar uma noção de letramento puramente linguístico, e reconhecer outros modos semióticos estreitamente relacionados à leitura e à escrita. Um dos estudos citados pelo autor, por exemplo, teve como tema a utilização de filmes em salas de aula de escolas secundárias na Inglaterra. Ao longo do estudo, a pesquisadora se deu conta de como a utilização de filmes possibilitou a construção de um "metaconhecimento" (STREET, 2005, p.12) por parte dos alunos, através do qual estes eram capazes de comparar versões distintas de um mesmo texto canônico em diferentes mídias - um "metaconhecimento" que, segundo Street, os alunos dificilmente teriam obtido se o foco das aulas tivesse se restringido ao uso de letramentos tradicionais como a escrita, por exemplo. 
A nós, professores, cabe o desafio de problematizar em sala de aula os usos e as implicações de letramentos tão diversos quanto a escrita acadêmica, o tweet ou o mangá, entre tantos outros. Isso requer, como sugere Street (2005), diminuir a distância entre o aprendizado formal, institucionalizado da sala de aula, e o aprendizado informal que acontece, por exemplo, no ambiente familiar do aluno, ou no convívio com amigos em situações de lazer, quando a comunicação virtual em salas de bate-papo na internet ou através de jogos online propiciam o desenvolvimento de um letramento muitas vezes ignorado ou até mesmo desvalorizado pelo professor em sala de aula. Mas também requer, segundo Menezes de Souza (2011), desnaturalizar ideias, crenças e conhecimentos do senso comum, "levar o aluno a refletir sobre a história, sobre o contexto de seus saberes" (2011, p.293), para que ele perceba como aquilo que lhe parece natural pode ser estranho, incompreensível ou até hostil para alguém situado em outro contexto diferente do seu. Essa reflexão - também no sentido de reflexividade apontado acima - pode, ainda segundo Menezes de Souza, educar para a diferença e para o conflito entre visões e leituras de mundo diferentes, conscientizando o aluno das consequências éticas de suas ações e interpretações - algo de suma importância no mundo globalizado, multimodal e híbrido em que vivemos atualmente.

\section{REFERÊNCIAS BIBLIOGRÁFICAS}

BRASIL. Projeto Político Pedagógico do Curso de Letras. Universidade Federal de Uberlândia, 2007.

COPE, B.; KALANTZIS, M. Multiliteracies: literacy learning and the design of social futures. London: Routledge, 2000.

CUNHA, M.C. Cultura entre aspas. São Paulo: Cosac \& Naify, 2009.

GEE, J. P. Situated language and learning. A critique of traditional schooling. New York and London: Routledge, 2004.

KRESS, G. \& van LEEUWEN, T. Reading images. The grammar of visual design. London \& New York: Routledge, 1998.

KRESS, G. "Multimodality" In: Multiliteracies. Literacy learning and the design of social futures. London and New York: Routledge, 2000.

KRESS, G. Multimodality: A social semiotic approach to contemporary communication. London and New York: Routledge, 2009. 
MENEZES DE SOUZA, L.M.T. "Para uma ecologia da escrita indígena: a escrita multimodal kaxinawá”. In Signorini,I. (org.). Investigando a Relação Oral/Escrito. Campinas: Mercado de Letras, 2001.

MENEZES DE SOUZA, L.M.T. “As visões da anaconda: a narrativa escrita indígena no Brasil”. Revista Semear no.7, PUC-RJ, 2002.

MENEZES DE SOUZA, L.M.T. "O professor de inglês e os letramentos no século XXI: métodos ou ética?" In: Jordão, C.M., Martinez, J.Z. \& Halu, R.C. (orgs.) Formação “desformatada”. Práticas com professores de lingua inglesa. Campinas: Pontes Editores, 2011.

ROSE, G. Visual methodologies. An introduction to the interpretation of visual materials. London, Thousand Oaks and New Delhi: Sage Publications, 2007.

STREET, B. (ed.) Literacies across educational contexts. Mediating learning and teaching. Philadelphia: Caslon Publishing, 2005.

SWALES, J. M. Genre analysis. English in academic and research settings. 6a. ed. Cambridge: Cambridge University Press, 1999. 